\title{
OBITUARY
}

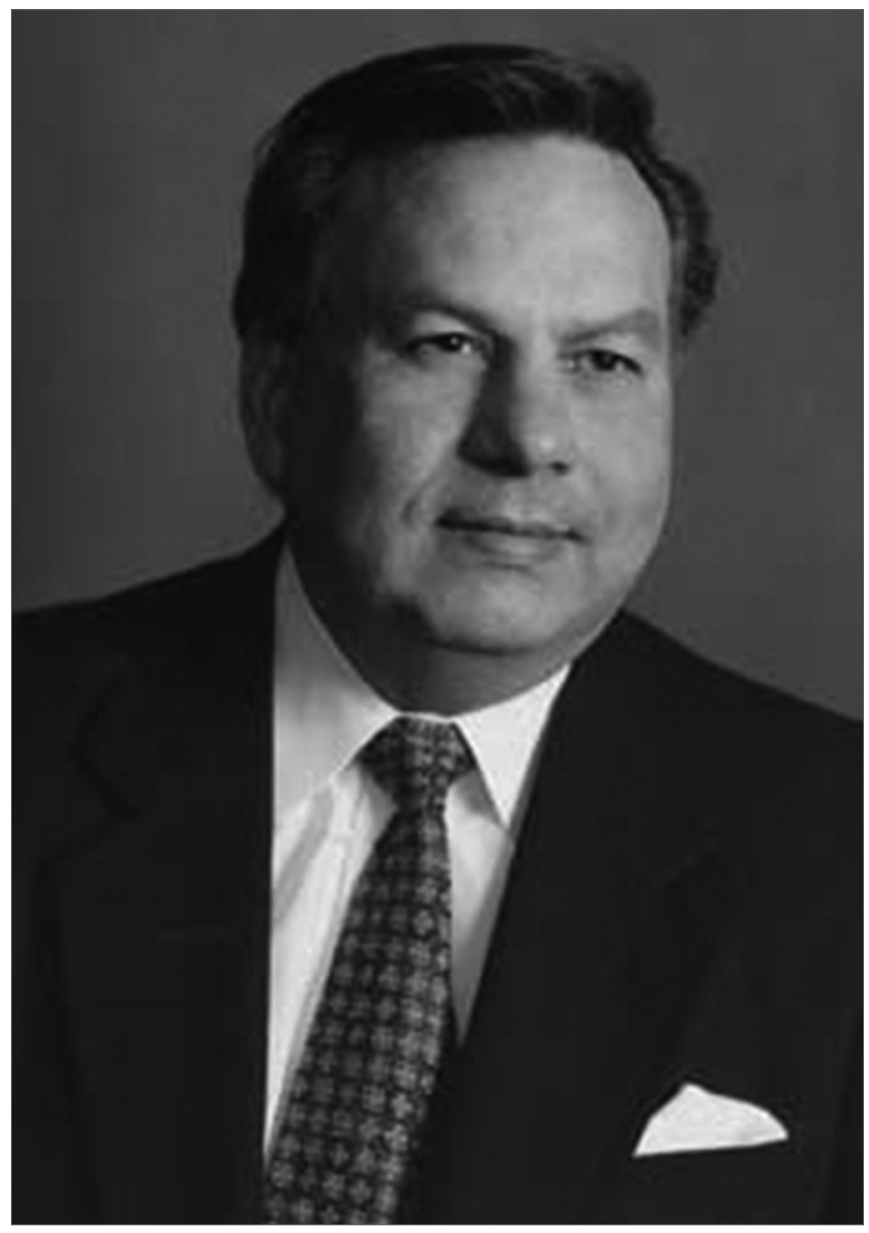

The Brazilian Journal of Otorhinolaryngology is honored to pay homage to the most transcontinental of otologists, the great friend of Brazil, Antonio De la Cruz, who died suddenly on July 31, 2009, causing deep sorrow among his friends and colleagues from the world over, leaving behind a whole cadre of students and admirers, who have now become orphans of one of the most outstanding references in the entire history of otology. His teachings, his kindness and his gentle soul will certainly be missed.

\section{Antonio De la Cruz}

$\star 1944$

$\dagger 2009$ 